\title{
O ensino da teoria sociológica em alguns cursos de Ciências Sociais de universidades públicas brasileiras
}

Márcio de Oliveira'

\section{Resumo}

Este artigo tem por objeto analisar o lugar que o ensino da teoria sociológica ocupa nos cursos superiores de Ciências Sociais, a partir do estudo de caso em algumas universidades públicas brasileiras (Ceará, Pernambuco, Brasília, São Paulo, Rio de Janeiro, Paraná, Santa Catarina e Rio Grande do Sul). Para isso, inicialmente, analisamos a história dos estudos teóricos, mapeamos os grupos de pesquisa e mostramos que a pesquisa ocupa um espaço secundário na Sociologia brasileira. Analisando as grades curriculares dos cursos e as ementas das disciplinas teóricas, mostramos que há muito espaço e tempo dedicado à teoria sociológica, em especial à teoria clássica, nos quatro primeiros semestres. Mostramos que esse espaço, para os autores clássicos, apresenta formato e conteúdo semelhantes (em geral, Marx, Weber e Durkheim), mas que são bem diversos em relação aos autores contemporâneos. Apesar da grande importância e do tempo dedicado ao ensino da teoria, não há discussões formais sobre como ensinar em termos metodológicos e epistemológicos.

Palavras-chave: Curso de Ciências Sociais. Ensino. Teoria sociológica. Universidade.

\section{Introdução}

Nos últimos anos, a partir das novas orientaçóes dos Parâmetros Curriculares Nacionais (PCNs) definidas pelo Ministério da Educação (MEC) ${ }^{2}$, as discussóes sobre os conteúdos a serem ensinados em aulas de Sociologia no Ensino Médio ganharam bastante destaque. A Sociedade Brasileira de Sociologia também vem participando desse esforço, tendo, inclusive, criado um fórum de debates permanente sobre o tema ${ }^{3}$. Contudo, todos esses debates

Professor Titular de Sociologia da Universidade Federal do Paraná,Brasil.E-mail:marciodeoliveira@ufpr,br

2 Esse compromisso foi firmado após a aprovação, pelo Conselho Nacional da Educação (2006), do retorno do ensino de Sociologia e Filosofia ao Ensino Médio.

3 A entidade está presente igualmente nas discussões realizadas no âmbito do programa de incentivo à docência no Ensino Médio (PIBID). A este respeito, ver a "Carta Aberta do Encontro Nacional do PIBID Ciências Sociais/ Sociologia", no sítio web da entidade. 
têm por foco as metodologias de sala de aula e os temas específicos (violência, gênero, juventude, cidadania, meio ambiente, entre outros), não particularizando o ensino da teoria sociológica (CARVALHO, 2004, 2008; SILVA, 2010; OLIVEIRA, 2013). Mesmo no dossiê sobre o ensino da Sociologia assim como no volume dedicado à Sociologia, no interior da coleção "Explorando o ensino" (MEC), ambos organizados por Moraes (2003, 2010), o ensino da teoria sociológica e/ou a discussão metodológica sobre as formas de ensinar a teoria também estão ausentes.

No Ensino Médio, como se pode deduzir de materiais produzidos por professores $^{4}$, dos livros analisados no Guia Nacional do Livro Didático (BRASIL, $2014)^{5}$ ou de alguns manuais de Sociologia escritos em português, hoje disponíveis no mercado (COSTA, 1987; OLIVEIRA, 2001; FERREIRA, 2003; OLIVEIRA, 2007; ARAÚJO; BRIDI; MOTIM, 2010), a teoria ensinada resume-se a uma apresentação de temas das obras dos autores clássicos mais consagrados, Marx, Weber e Durkheim ${ }^{6}$ ou, ainda, apresenta os autores a partir do tema da modernidade - como é o caso do livro "Tempos modernos e tempos de sociologia" de Helena Bomeny et al. (2013) - ou do tema religiáo - por exemplo, em Araújo, Bridi e Mottim (2013). É de se pensar que a apresentação aprofundada da teoria sociológica náo caberia nesse nível, visto que o objetivo é introduzir a disciplina de uma forma atual e interativa, diferente assim da perspectiva adotada no Ensino Superior. O que ocorre então neste outro nível de ensino? Em geral, o formato dos cursos de Ciências Sociais inicialmente prepara os alunos teórica e metodologicamente, para, depois, levá-los às práticas de pesquisa durante os últimos semestres, pela realização do Trabalho de Conclusão do Curso (TCC) ou através das experiências de pesquisa no interior dos grupos dos professores. $\mathrm{O}$ ensino da teoria sociológica no Ensino Superior, tanto nos bacharelados quanto nas licenciaturas, simplesmente não vem sendo objeto de debates nacionais, nem mesmo no interior da

4 A título de exemplo, o estado do Paraná encomendou a seus professores um manual. Das 280 páginas do texto, apenas 18 são dedicadas à teoria sociológica e resumem-se a aspectos gerais das obras de Marx. Weber e Durkheim. Na bibliografia, ver "Sociologia"”.

5 Na edição 2015 do Guia Nacional, Sociologia, foram analisados seis liuros impressos e quatro digitais. O Guia $e$ as análises estão disponíveis no sítio do Fundo Nacional de Desenvolvimento da Educação: <http://www. fnde.gou.br/programas/liuro-didatico/guias-do-pnld/item/5940-guia-pnld-2015>.

6 Uma escolha que sempre deixa "de lado" outros autores clássicos da Sociologia, como Georg Simmel, por exemplo. 
recentemente criada Associação Brasileira de Ensino de Ciências Sociais ${ }^{7}$. Para se possibilitar uma visão mais completa do assunto, decidimos investigar os diversos grupos de pesquisa em teoria no Diretório de Grupos de Pesquisa do CNPq. Percebemos que o tema da teoria vem sendo efetivamente trabalhado, mas ultrapassa em muito o escopo deste artigo estabelecer a relação entre essas pesquisas e a realidade de sala de aula.

Por isso, mais modestamente, mostramos aqui que há muito espaço e tempo dedicado à teoria sociológica nos quatro primeiros semestres dos cursos de Ciências Sociais no Ensino Superior brasileiro. Como um todo, o ensino das teorias clássica e contemporânea tem formato semelhante - apresentação da obra dos autores por meio de trechos ou capítulos selecionados - seja nas disciplinas obrigatórias a eles dedicadas, seja nas disciplinas optativas. Além disso, nas ementas das disciplinas optativas da Sociologia, há sempre um momento inicial de exposição dos textos teóricos - clássicos e contemporâneos - fundadores daquele subcampo. Paradoxalmente, contudo, embora os clássicos continuem sendo muito ensinados na graduação e citados nas teses de pós-graduação ${ }^{8}$, praticamente não se discute o ensino da teoria em sala de aula, ou seja, a análise das ementas das disciplinas obrigatórias dos cursos selecionados mostra que há pouca reflexão epistemológica e/ou metodológica sobre as formas de se estudar e de se apresentar a teoria. Talvez essa realidade seja consequência da pequena institucionalização da pesquisa em teoria. Com efeito, são poucos os grupos de pesquisa registrados hoje no Diretório de Grupos do Conselho Nacional de Pesquisa Científica (CNPq), que se dedicam exclusivamente a pesquisar teoria sociológica. Em resumo, os autores são ensinados, mas não se discutem os métodos para esse tipo de ensino. Da mesma maneira, a pesquisa em teoria não aparece como campo específico. A teoria sociológica teria, então, se tornado uma referência incontornável, mas não epistemologicamente problematizada? Este artigo enfrenta essas questóes, procurando responder: "quem são os teóricos clássicos e contemporâneos mais estudados nos cursos de Ciências Sociais no Brasil de hoje? Que lugar e quanto

7 Para maiores informações, acesse: <www.abecs.com.br>.

8 Em um artigo sobre autores clássicos citados por um minimo de 30 teses defendidas entre 199I e 1993 na área de Ciências Sociais e estudos agrários, Melo (1999, p. 305) afirma que Max Weber aparece em $2^{\circ}$ lugar, com 97 citações; Marx em $3^{\circ}$, com 95 citações; e Durkheim em $8^{\circ}$ lugar, com 69 citações. 
tempo, na grade curricular, são reservados aos teóricos? Quais os conteúdos mais presentes?".

Apresentamos uma análise comparativa e não exaustiva sobre o lugar da teoria sociológica (clássica e contemporânea) em alguns cursos de graduaçáo em Ciências Sociais no Brasil, selecionados de norte a sul do Brasil em função das informações disponíveis nos sítios de internet, fato que permitiu mas também limitou nossa análise. Para efeitos deste trabalho, limitamo-nos aos cursos de Ciências Sociais das instituiçóes públicas, com foco na formação do

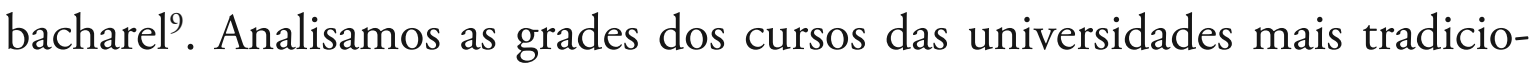
nais, mas também investigamos cursos de outras instituiçôes, procurando respeitar a diversidade nacional. A escolha recaiu nos primeiros cursos de Ciências Sociais criados no Brasil, casos da Universidade de São Paulo (USP) e do Rio de Janeiro (UFRJ). Desse momento em diante, escolhemos os cursos da Universidade de Brasília (UnB), e das Universidades Federais do Ceará (UFC) e Pernambuco (UFPE), no Nordeste, e do Rio Grande do Sul (UFRGS), de Santa Catarina (UFSC) e do Paraná (UFPR), do sul do país. Nos cursos selecionados, retiramos as informações trabalhadas dos próprios sítios mantidos pelas universidades e pelos referidos cursos, já sabendo, de antemáo, que essas informaçóes podem, eventualmente, náo corresponder exatamente à realidade de cada instituiçáo. Cientes dessa dificuldade, com os dados colhidos, nós analisamos ementas, bibliografias e comparamos os semestres em que se encontram as disciplinas teóricas nas grades curriculares.

Abrimos esse artigo por uma contextualização sumária dos debates teóricos na Sociologia brasileira e por uma apresentação geral da pesquisa em teoria a partir da base de dados dos grupos de pesquisa registrados no Conselho Nacional de Pesquisa Científica (CNPq).

\section{A pesquisa em teoria sociológica no Brasil}

Os livros e artigos sobre a história da Sociologia no Brasil (CÂNDIDO, 1957; MENEZES, 1965; CHACON, 1977; NOGUEIRA, 1981; MICELI, 1989, 1995, 1999; PESSANHA; VILLAS-BÔAS, 1995; LIEDKE FILHO, 2005; VILLAS-BÔAS, 2007) não mencionam, em detalhes, a trajetória do

9 Como regra geral, a formação de bacharel exclui as disciplinas pedagógicas e não habilita o formado à prática docente no Ensino Médio; logo, para tal atividade, o aluno tem de se formar em licenciatura. 
campo da pesquisa em teoria sociológica. Não obstante, a pesquisa em teoria sociológica está na origem e perpassa toda a obra de Florestan Fernandes. Aluno da primeira geração de professores estrangeiros - Lévi-Strauss, Roger Bastide, Donald Pierson, entre outros - o sociólogo paulista dedicou-se de maneira específica à teoria sociológica traduzindo (Marx, por exemplo) e publicando quatro livros específicos sobre a questão: Fundamentos Empiricos da Explicação Sociológica (1959), Ensaios de Sociologia Geral e Aplicada (1960), Elementos de Sociologia Teórica (1970) e A natureza sociológica da Sociologia (1980). Publicou, ainda, inúmeros artigos e coordenou a coleção "Grandes Cientistas Sociais", ainda hoje uma referência acadêmica e editorial em língua portuguesa para os estudos dos autores clássicos e contemporâneos de Ciências Sociais ${ }^{10}$. No início de sua formação, tanto em sua dissertação de mestrado quanto em suas teses de doutorado e de livre-docência, transformadas posteriormente em livros, grandes foram os espaços dedicados à discussão teórica. É o que abordaremos a seguir.

A dissertação de mestrado e a tese de doutorado versaram sobre a sociedade Tupinambá. Simplificando, podemos afirmar que, no trabalho de mestrado de Fernandes (1949) - A organizaçâo social dos Tupinambá -, há uma disposição de compreender a totalidade da organização indígena a partir de fontes secundárias, enquanto que na tese de doutorado está em questão a função da guerra como fato social total, ou seja, a guerra enquanto fato que permite compreender a trajetória social e história daquela sociedade indígena. Em ambas as obras, a perspectiva funcionalista é clara. Peirano (1992, p. 54-84) defende que esses trabalhos devem ser compreendidos como a fase antropológica de Fernandes. Contudo, naqueles anos, as três áreas das Ciências Sociais ainda estavam em processo de afirmação. Assim, Fernandes leu, releu e debateu indistintamente os principais clássicos da Sociologia, da Ciência Política e da Antropologia, espelhando, de certa forma, o mundo acadêmico de pouca diferenciação disciplinar da primeira metade do século XX. A título de ilustração, podemos lembrar que os debates teóricos em torno dos fundamentos funcionalistas da explicação sociológica, travados por Fernandes $(1949,1952)$ tanto na dissertação de mestrado quanto na tese de doutorado, têm por fundamento

10 Ver, também, A organização social dos Tupinambá (FERNANDES, 1949) e A Função Social da Guerra (FERNANDES, 1952). 
os trabalhos escritos e discutidos conjuntamente por Emile Durkheim e Marcel Mauss nos anos em que estes viveram na cidade de Bordeaux (França) ${ }^{11}$ :

O referencial teórico nesses dois trabalhos oscila entre Durkheim (especialmente as obras A Divisão do Trabalho Social DTS, e As Regras do Método Sociológico RMS) e Mauss (Manuel d'Ethnographie; Essaissurle Don; Essaissurlesvariationssaisonières.). Em ambos, chama a atenção o pequeno número de referências diretas a Durkheim. Não obstante, a inspiração é inegável, assentada tanto no conceito de representações, utilizado já em 1943 , quanto no método funcionalista. Segundo ele, o método funcionalista era quem permitia "reconstruir as situações sociais e os comportamentos individuais ou coletivos desencadeados pela guerra, ligá-los entre si de modo coerente com o contexto social e explicar causalmente a emergência e os efeitos sociais da guerra" (Fernandes, 1970: 17). Anos mais tarde, Fernandes (1959) reúne em um mesmo livro diversos trabalhos, publicados entre 1953 e 1957, sobre os problemas da explicação sociológica - de fato, sobre os problemas da indução em Sociologia - nos três clássicos da Sociologia, Marx, Weber e Durkheim. A lógica indutiva de Durkheim é analisada a partir de RSM e Montesquieu et Rousseau. Precurseurs de la Sociologie. Ao final, Fernandes (1973: 83) afirma que a "ideia fundamental das RMS consiste em que há entre os fenômenos sociais uma ordem própria, uma ordem sujeita ao determinismo, isto é, uma ordem causal”. (OLIVEIRA, M. de, 2013).

Com efeito, os Fundamentos Empiricos da Explicação Sociológica (FERNANDES, 1959) não apresentam uma filiaçáo ou escolha teórica definitiva, mas antes a maturidade intelectual do sociólogo paulista e talvez mesmo seu desejo de participação na arena política ${ }^{12}$. A importância conferida aos três clássicos da teoria sociológica, consolidada naqueles anos, permaneceria como um dos legados mais importantes de Fernandes para a Sociologia brasileira. Mas se o sociólogo paulista é sempre um caso ímpar e paradigmático, sua obra não é um caso isolado. $\mathrm{O}$ interesse pela teoria sociológica esteve presente em vários autores de sua própria época e posteriores, tais como: Fernando de Azevedo, Raimundo Faoro, Maria Isaura Pereira de Queiroz, Fernando Henrique Cardoso, Otávio Ianni, Marialice Foracchi, Gabriel Cohn, entre outros. Como exemplos dessa nova "fornada", elegemos os casos de Raimundo Faoro, Maria Isaura, Fernando Henrique e Otávio Ianni como os mais exemplares da

II Para uma melhor apreciação da estreita relação pessoal entre Durkheim e Mauss, ver, entre outros, as biografias assinadas por Marcel Fournier $(1994,2007)$ e o recente trabalho de Mathieu Béra (2014) sobre os anos bordelenses de Durkheim.

12 Veras (2014) chama a atenção para as epigrafes "conflitantes" de Durkheim e Marx nesse trabalho, reconhecendo ai a "dupla problemática teórica e prática do conhecimento" em Fernandes. 
presença da teoria clássica naqueles anos. Os quatro, cada um à sua maneira, valeram-se de maneira criativa e não sectária dos três clássicos nas escolhas teóricas que fizeram nos anos 1950 e 1960, escolhas estas que marcaram o desenvolvimento da Sociologia no Brasil. Embora seja sempre difícil individualizar influências teóricas, mesmo um leitor desavisado de obras desses autores encontra facilmente referências a Weber em Os donos do Poder de Faoro (1989). A Sociologia de Durkheim está presente nos trabalhos de Maria Isaura Pereira de Queiroz. A título de exemplo, temos a segunda tradução das Regras do Método Sociológico passando pela importância de compreender historicamente os "fatos sociais", em especial o fato religioso, perspectiva adotada nos estudos sobre os movimentos messiânicos, até finalmente um pequeno artigo em que a socióloga paulista revisita criticamente a teoria de Durkheim (QUEIROZ, $1995)^{13}$. Moldado pelo marxismo teórico e profundamente preocupado com as questóes de desenvolvimento ${ }^{14}$, os trabalhos de Fernando Henrique Cardoso, desde o clássico Capitalismo e escravidáo no Brasil Meridional, devem muito aos estudos de $O$ Capital (RODRIGUES, 2011). Marx está presente ainda nos trabalhos de Ianni, desde sua tese de doutorado - O negro na sociedade de castas - transformada no livro As metamorfoses do Escravo (1962) ${ }^{15}$, passando por Estado e capitalismo no Brasil (1965) e Dialética e capitalismo: ensaio sobre o pensamento de Marx (1982), para citar apenas esses.

Dos três clássicos, porém, Karl Marx e Max Weber foram aqueles que geraram, desde as décadas de 1950 e 1960, mais estudos e também mais estudiosos além de seguidores, dentre os sociólogos brasileiros. Essa predileção fortaleceu-se com o tempo, no caso de Weber (COHN, 2003; SOUZA, 2000; PIERUCCI, 2003; VILLAS-BÔAS, 2006; SELL, 2014), e se ampliou, no caso de Marx, aos diversos centros de estudos marxistas (HALLEWELL; LESSA, 1998; BOITO JR.; MOTTA, 2010). Já Georg Simmel e Emile Durkheim começaram a ser mais tardiamente estudados, mas vem sendo

13 É possivel afirmarmos, ainda, a partir de Bôas (2010) e Botelho e Carvalho (20II), que o tema da mudança social, tão caro para Maria Isaura, foi pensado, também, dentro de uma referência durkheimiana. Na trajetória de grupos sociais primários ou rurais, havia relações de solidariedade e de reciprocidade.

14 Ver a esse respeito, nas referências bibliográficas, a entrevista de Fernando Henrique Cardoso, concedida a Pedro Luiz Lima (2013).

15 Ianni, tal como Fernando Henrique Cardoso, Fernando Novais, Paul Singer, entre outros, também participou do grupo de estudos Seminário Marx, idealizado por José Arthur Giannotti, que se reuniu entre 1958 e 1964. para ler e discutir "O Capital". Ver Rodrigues, 2011. 
objeto de apresentaçóes e pesquisas específicas (MORAES FILHO, 1983; WAIZBORT, 2000, 2007; SOUZA; ÖLZE, 2005; RODRIGUES, 1977; WEISS, 2012, 2013; OLIVEIRA, 2010, 2012; OLIVEIRA; WEISS, 2011). Enfim, um grande número de outros autores - Lukacs, Mannheim, Bourdieu, entre outros - foram objeto de estudos e apresentaçóes na conhecida "Coleção Grandes Cientistas Sociais", demonstrando, assim, que a teoria sociológica foi efetivamente recebida e está disponível ao estudante de Ciências Sociais no Brasil.

\section{0 estudo e a pesquisa em teoria atualmente}

Liedk Filho (2005) contabilizava em 2005, 32 grupos de pesquisa sobre o tema "Fundamentos da Sociologia". Hoje, em 2014, a busca pela expressão "Fundamentos da Sociologia" no Diretório de Grupos do $\mathrm{CNPq}^{16}$ nos reenvia somente quatro grupos, um deles na área de Educação e outro na área de Ensino da Sociologia. Quando a expressáo é "Teoria Sociológica", surgem 11 grupos, por exemplo, o Grupo de Estudos de Teoria Social (UNICAMP, 2008 ${ }^{17}$ ) e o Núcleo de Pesquisas e Estudos em Teoria Social (UFF, 2010 ${ }^{18}$ ). Modificando os critérios de busca e adicionando as expressóes "história da Sociologia" e "Epistemologia", surgem outros três grupos. Ao total, conforme ilustra o Quadro 1, temos 16 grupos, nem todos na área de Sociologia, como o grupo "Sociologia, Direito e Justiça", do Direito da Universidade Federal Fluminense. Chama a atenção, ainda, o ano de criaçáo. Dos 16 grupos a seguir, os mais antigos, apenas dois, foram criados nos 1990. A grande maioria, portanto, é de grupos jovens. 12 deles criados nos últimos seis anos, sendo sete desses 12, criados nos últimos dois anos. Assim, a produção desses jovens grupos é - e não poderia ser diferente - pequena. Finalmente, devemos ressaltar que os grupos consultados apresentam várias linhas de pesquisa, o que dilui, ainda mais, a produção específica em teoria.

16 Nessa base, fizemos busca com as expressões "Fundamentos da Sociologia" e "Teoria Sociológica".

17 Esse grupo tem duas linhas de pesquisa. Uma delas tem por título "Epistemologia das Ciências Humanas".

18 Nesse grupo, a pesquisa em teoria não figura no título de nenhuma das duas linhas de pesquisa, uma dedicado à luta pela terra nos "campos de Goytacazes" e a outra dedicada ao estudo dos movimentos sociais. 


\section{Quadro I - Grupos de pesquisa em teoria sociológica em atividade}

\begin{tabular}{|c|c|c|c|}
\hline Nome do Grupo & $\begin{array}{l}\text { Ano de } \\
\text { criação }\end{array}$ & Instituição & $\begin{array}{l}\text { Linha(s) de pesquisa dedicadas à teoria } \\
\text { sociológica }\end{array}$ \\
\hline Sociologia: História e paradigmas & 1992 & UFRGS & História da teoria sociológica \\
\hline $\begin{array}{l}\text { Núcleo de Cidadania, Exclusão } \\
\text { e Processos de mudança }\end{array}$ & 1995 & UFPE & Teoria sociológica \\
\hline $\begin{array}{l}\text { Sociedade, representações e } \\
\text { processos sociais }\end{array}$ & 2000 & UFPEL & Teoria sociológica contemporânea \\
\hline Sociologia, Direito e Justiça ${ }^{19}$ & 2004 & UFF & Teoria sociológica e do direito \\
\hline Núcleo de Pesquisa Sociofilo²0 & 2007 & UERJ & $\begin{array}{l}\text { Teoria sociológica como ontologia do } \\
\text { presente } \\
\text { As novas correntes da teoria social } \\
\text { Fundamentos filosóficos da teoria social }\end{array}$ \\
\hline Grupo de Estudos em Teoria social & 2008 & UNICAMP & Epistemologia das Ciências Humanas \\
\hline $\begin{array}{l}\text { Grupo de Pesquisas Processos } \\
\text { Civilizatórios }^{21}\end{array}$ & 2008 & UEL & História e Sociologia \\
\hline $\begin{array}{l}\text { Laboratório de Sociologia não } \\
\text { exemplar }\end{array}$ & 2009 & $\operatorname{Un} B$ & Teoria sociológica não exemplar \\
\hline $\begin{array}{l}\text { Interpretações do Brasil e } \\
\text { pensamento social }\end{array}$ & 2010 & UFRJ & Pensamento social e teoria sociológica \\
\hline Teoria crítica e Sociologia 22 & 2011 & UNICAMP & $\begin{array}{l}\text { Teoria crítica e Sociologia } \\
\text { Teoria social contemporânea } \\
\text { Teoria sociológica }\end{array}$ \\
\hline $\begin{array}{l}\text { Estudos teóricos de Sociologia } \\
\text { Contemporânea }\end{array}$ & 2012 & UFAM & Teoria Sociológica \\
\hline $\begin{array}{l}\text { Grupo de Pesquisa sobre } \\
\text { Governo, Ética, e Subjetividade }\end{array}$ & 2012 & USP & Teoria Sociológica \\
\hline $\begin{array}{l}\text { Télos - Grupo de pesquisa em } \\
\text { Ciências Humanas }\end{array}$ & 2012 & UFRR & $\begin{array}{l}\text { Pensamento social e questão de } \\
\text { método em teoria sociológica }\end{array}$ \\
\hline $\begin{array}{l}\text { Teoria sociológica e } \\
\text { pensamento marxista no Brasil }\end{array}$ & 2012 & $\begin{array}{l}\text { UNIFAP } \\
\text { (Amapá) }\end{array}$ & $\begin{array}{l}\text { Recepção das ideias lukacsianas no Brasil } \\
\text { Teoria sociológica contemporânea e } \\
\text { pensamento marxista no Brasil }\end{array}$ \\
\hline $\begin{array}{l}\text { Centro Brasileiro de Estudos } \\
\text { Durkheimianos }\end{array}$ & 2013 & UFRGS & $\begin{array}{l}\text { Sociologia das Ciências Sociais } \\
\text { Teoria }\end{array}$ \\
\hline $\begin{array}{l}\text { Núcleo de Estudos Comparados } \\
\text { e Pensamento social }\end{array}$ & 2013 & UFF & $\begin{array}{l}\text { Nos limites da razão funcionalista: } \\
\text { variações da teoria sociológica (1950-70) }\end{array}$ \\
\hline Grupo de Estudos em Bourdieu & 2014 & UNICAMP & Teoria e pensamento sociológico \\
\hline
\end{tabular}

Fonte: Diretório de Grupos CNPq (2014).

19 Esse grupo conta com 13 linhas de pesquisa bem diversas, desde os estudos sobre imigrantes, instituições judiciárias e policiais, mercado de trabalho, comunicação, demonstrando grande dispersão temática.

20 Esse grupo reúne seis pesquisadores e 19 estudantes. Tem como lider, o professor belga Frederic Vandenbergue, especialista em teoria sociológica e dono de vasta produção na área de teoria.

21 Registrado na área de Educação.

22 Trata-se do maior grupo de pesquisa nessa área, reunindo 15 pesquisadores e 15 estudantes. 
As consequências da realidade acima descrita são difusas e particulares, uma vez que os grupos de pesquisa são autônomos. Ademais, precisamos mencionar que a relação entre pesquisa e ensino em teoria náo é fácil de ser estabelecida. Ora, pode-se supor que o ensino da teoria derive da pesquisa em teoria, ora não.

Se a produção propriamente teórica parece ter perdido o grande fôlego que apresentou outrora, ela tem hoje seus fóruns específicos. Encontramos trabalhos teóricos nos Grupos de Trabalho (GT) sobre teoria sociológica tanto nos congressos da Sociedade Brasileira de Sociologia quanto nos encontros da Associação Nacional de Programas de Pós-graduação em Ciências Sociais (ANPOCS). Na Sociedade Brasileira de Sociologia, o GT de teoria de, desde 2007, tem acolhido uma média de 24 trabalhos a cada encontro ${ }^{23}$. No caso da Associaçáo Nacional de Programas em Ciências Sociais (ANPOCS), após a divisão dos espaços para apresentação de trabalhos, com a criação dos "Simpósios pós-graduandos", exclusivamente destinados aos alunos de pós-graduação, há dois grupos com o título de "Teoria social no limite: novas frentes/fronteiras na teoria social contemporânea”, perfazendo, em média, 15 pesquisadores e cinco estudantes de pós-graduação apresentando resultados de pesquisas em teoria. $\mathrm{O}$ número total vem sendo grande nesses fóruns, demonstrando a vitalidade da pesquisa. Todavia, de forma geral, não são muitos os autores a transformarem trabalhos apresentados em artigos publicados em revistas indexadas ${ }^{24}$. Finalmente, são pouco frequentes os números de revistas dedicados especificamente às questôes teóricas e aos autores clássicos, com exceção de $\mathrm{Marx}^{25}$. Logo, os autores clássicos continuam a ser pesquisados em nichos específicos ${ }^{26}$ ou a partir de iniciativas individuais.

\section{0 ensino da teoria: análise de alguns casos}

Em relação ao ensino, o lugar da teoria tem sido objeto de debates difusos e, aqui e ali, questiona-se o papel e o lugar das disciplinas teóricas nas grandes

23 Mesmo sem termos feito um levantamento específico, nosso conhecimento in loco permite afirmar que em outros GTs, há também trabalhos em teoria.

24 Isso pode estar indicando que esses trabalhos apresentados como "teoria" são apenas subprodutos das teses ou de pesquisas sobre outros assuntos.

25 No Brasil, assim como em outros países, os centros e grupos de pesquisa dedicados a Marx são numerosos. Da mesma forma, nos últimos 20 anos, as obras vêm sendo retraduzidas e republicadas, o que talvez demonstre que o interesse não esmoreceu ao longo do tempo.

26 Um bom exemplo disso é o "Centro Brasileiro de Estudos Durkheimianos" criado recentemente, em 2013. Para maiores detalhes, ver: <http://www.durkheim-br.org>. 
curriculares. Aparentemente, há um consenso, informalmente construído, em relaçáo à importância do ensino das teorias clássica e contemporânea nos cursos de Ciências Sociais. Por outro lado, há uma posiçáo praticamente oposta - é difícil dizer o quanto ela é representativa. Além disso, o quadro que mostramos a seguir revela que ela náo se traduz nas grades curriculares - sobre certo "excesso de teoria" e ausência de disciplinas de método, em especial quantitativos, nos primeiros semestres de nossos cursos. E as duas posiçóes - importância ou excesso de teoria nos primeiros semestres - revelam diagnósticos diametralmente opostos sobreo público egresso do Ensino Médio. Os primeiros acreditam que o ensino da Sociologia no Ensino Médio estaria enviando às universidades alunos com certa bagagem em Ciências Sociais; os últimos afirmam o contrário, ou seja, que nossos alunos, egressos do Ensino Médio e socializados segundo critérios de aprendizagem pautados pelos exames universitários de seleçáo e pelas informaçôes virtuais, não teriam maturidade suficiente para enfrentar o desafio intelectual que representa o ensino dos clássicos das três áreas de Ciências Sociais (Antropologia, Ciência Política e Sociologia), logo nos dois primeiros anos de formação.

Enquanto os defensores da importância do ensino da teoria valem-se, regra geral, de argumentos tais como a necessidade de se estudar os fundadores da disciplina, seus críticos têm apresentado novos argumentos:

1. Os cursos de CS no Brasil são antes eruditos do que técnicos, originários dos centros e faculdades de Filosofia e Letras.

2. Os autores clássicos recebem muito mais atenção dos que os autores contemporâneos.

3. O espaço dedicado aos autores contemporâneos é cada vez menor em relaçáo ao número de novos autores, muitos deles egressos de países como a Índia, China ou Austrália, outrora praticamente ignorados. E o formato dos cursos de Ciências Sociais no Brasil ${ }^{27}$ - divididos nas três áreas, Antropologia, Ciência Política e Sociologia - os obriga a pesadas e, por vezes, desconexas leituras de grande número de clássicos.

4. A quantidade de textos é grande e, por vezes, desconexa ${ }^{28}$.

27 A título de exemplo, na Argentina, há formação em Ciências Sociais é separada por área.

28 É de se pensar, porém, se a grande carga de leituras, imaturidade intelectual dos alunos, desconexão com o dito mundo jovem etc. seriam problemas específicos dos cursos de Ciências Sociais. Que dizer dos cursos de Direito ou Medicina? Seriam eles mais fáceis e menos trabalhosos? 
5. Para além do grande número de autores, aponta-se para a dificuldade de compreensão e operacionalizaçáo das teorias clássicas e contemporâneas, ou seja, para a falta de um conhecimento da realidade atual que permita estabelecer a relação entre a teoria e a prática de pesquisa ${ }^{29}$;

6. As teorias clássicas, particularmente elas, estariam distantes do mundo dos jovens, absorvidos pela virtualidade das interaçóes e pelas chamadas redes sociais.

Colocados os argumentos nesses termos, tem-se o pior dos mundos: muito espaço dedicado ao ensino da teoria aliado ao pequeno número de pesquisadores nacionais que se dedica à pesquisa em teoria. Assim, afirmam os críticos do suposto excesso de teoria, o ensino da teoria segue caminhos já conhecidos, sem inovaçáo nem tentativas de aplicação.

Os argumentos daqueles que julgam excessivo o espaço dedicado à teoria não questionam, por exemplo, a forma como ocorre o ensino teórico, nem mesmo seu lugar nas grades curriculares. Em geral, esses argumentos se limitam a questionar a quantidade de textos e autores, a aparente dissociação em relaçáo à pesquisa empírica e a pouca importância dada à metodologia. Também não se questiona a falta de interação das três áreas que têm tradições distintas de recepção e de apropriação de autores. Não são questionadas, enfim, a ausência de espaços institucionais consolidados de pesquisa em teoria e a necessidade de intensa atualizaçáo, como se o ensino da teoria sociológica fosse natural e tranquilo para qualquer pesquisador/professor com título de doutor. Pode-se perguntar: dos que ensinam teoria regularmente, quanto tempo dedicam ao estudo, quantos projetos de pesquisa realizam ou quantos alunos orientam? $\mathrm{O}$ cruzamento dos dados dos grupos de pesquisa dedicados à teoria com os professores elencados para as disciplinas teóricas mostra que não há uma relação direta aí, ou seja, nem sempre os pesquisadores em teoria ministram aulas de teoria. Pode-se questionar, ainda, se há uma politica de recrutamento para efetivamente alocar pesquisadores em teoria nas disciplinas teóricas.

\section{As grades curriculares}

Analisamos, agora, as grades curriculares dos cursos selecionados. Observamos, primeiramente, o lugar que o ensino das teorias clássica e contemporânea ocupa e o tempo a elas dedicado. Em seguida, trabalhamos as ementas, analisando, ainda, os textos e livros selecionados para a leitura.

29 Tema abordado no artigo "Nas trincheiras do método: o ensino de metodologia das Ciências Sociais no Brasil" (CANO, 20I2). 


\section{Quadro 2 - Comparativo das grades curriculares dos Cursos de Ciências Sociais selecionados}

\begin{tabular}{|c|c|c|c|c|}
\hline & 10 Semestre & $2^{\circ}$ Semestre & $3^{\circ}$ Semestre & $4^{\circ}$ Semestre \\
\hline UFC & $\begin{array}{l}\text { Sociologia I História da } \\
\text { disciplina }\end{array}$ & $\begin{array}{l}\text { Sociologia II } \\
\text { Marx } \\
\text { Weber } \\
\text { Durkheim }\end{array}$ & $\begin{array}{l}\text { Sociologia III } \\
\text { Goffman } \\
\text { Bourdieu } \\
\text { Foucault } \\
\text { Senn } \\
\text { Habermas } \\
\end{array}$ & -- \\
\hline UFPE & $\begin{array}{l}\text { Fundamentos da } \\
\text { Sociologia }\end{array}$ & $\begin{array}{l}\text { Teoria Sociológica I Marx } \\
\text { Weber } \\
\text { Durkheim }\end{array}$ & $\begin{array}{l}\text { Teoria Sociológica II } \\
\text { Parsons } \\
\text { Mead Park } \\
\text { Garfunkel } \\
\text { Blum } \\
\text { Goffman } \\
\text { Gramsci } \\
\text { Escola de Frankfurt }\end{array}$ & $\begin{array}{l}\text { Teoria Sociológica III } \\
\text { Bourdieu } \\
\text { Giddens } \\
\text { Elias } \\
\text { Alex } \\
\text { Tocquev } \\
\text { Pós-Modernismo Pós- } \\
\text { Colonialismo }\end{array}$ \\
\hline UFRJ ${ }^{30}$ & $\begin{array}{l}\text { Sociologia Geral } \\
\text { Emergência do } \\
\text { pensamento sociológico } \\
\text { Introdução aos clássicos } \\
\text { conceitos básicos } \\
\end{array}$ & $\begin{array}{l}\text { Sociologia I - Conceitos } \\
\text { básicos e perspectiva de } \\
\text { análise sobre a sociedade; } \\
\text { transf. Modernas e } \\
\text { contemporâneas. }\end{array}$ & $\begin{array}{l}\text { Sociologia II } \\
\text { Modos como } \\
\text { a Sociologia } \\
\text { contemporânea trata } \\
\text { temas do presente. }\end{array}$ & $\begin{array}{l}\text { Sociologia III } \\
\text { Condições sociais de } \\
\text { Produção do } \\
\text { pensamento } \\
\text { Sociológico no Brasil }\end{array}$ \\
\hline UnB & Introdução à Sociologia & $\begin{array}{l}\text { Introdução à Metodologia } \\
\text { das Ciências Sociais }\end{array}$ & $\begin{array}{l}\text { Teoria Sociológica I } \\
\text { Tocqueville } \\
\text { Marx e Durkheim } \\
\end{array}$ & $\begin{array}{l}\text { Teoria Sociológica II } \\
\text { Weber e Simmel }\end{array}$ \\
\hline USP & $\begin{array}{l}\text { Sociologia I } \\
\text { História } \\
\text { Conceitos }\end{array}$ & $\begin{array}{l}\text { Sociologia II } \\
\text { Marx }\end{array}$ & $\begin{array}{l}\text { Sociologia III } \\
\text { Durkheim }\end{array}$ & $\begin{array}{l}\text { Sociologia IV } \\
\text { Sociologia Alemã }\end{array}$ \\
\hline UFPR & $\begin{array}{l}\text { Sociologia e } \\
\text { modernidade - } \\
\text { Paradigma marxista }\end{array}$ & $\begin{array}{l}\text { Sociologia e modernidade } \\
\text { - Paradigma weberiano }\end{array}$ & $\begin{array}{l}\text { Sociologia e } \\
\text { modernidade - } \\
\text { Paradigma durkheimiano }\end{array}$ & \\
\hline UFSC & $\begin{array}{l}\text { Introdução à Sociologia } \\
\text {-História e conceitos } \\
\text { centrais }\end{array}$ & $\begin{array}{l}\text { Teoria Sociológica. I } \\
\text { Sociologia Positivista de } \\
\text { Durkheim } \\
\text { Material histórico de Marx }\end{array}$ & $\begin{array}{l}\text { Teoria Sociológica II - } \\
\text { Sociologia compreensiva } \\
\text { de Weber e estrutural - } \\
\text { MN funcionalismo de } \\
\text { Parsons e Merton }\end{array}$ & $\begin{array}{l}\text { Teoria Sociológica III } \\
\text { Bourdieu } \\
\text { Escola de Frank } \\
\text { Foucault } \\
\text { Latour } \\
\end{array}$ \\
\hline UFRGS & $\begin{array}{l}\text { Sociologia I } \\
\text { História } \\
\text { Temas e conceitos } \\
\text { Agenda atual } \\
\end{array}$ & $\begin{array}{l}\text { Sociologia II } \\
\text { narrativa da Sociologia } \\
\text { marxista, compreensiva e } \\
\text { funcionalista }\end{array}$ & $\begin{array}{l}\text { Sociologia III } \\
\text { Contribuições } \\
\text { contemporâneas } \\
\text { Epistemologia das CS }\end{array}$ & \\
\hline
\end{tabular}

Fonte: Elaborado pelo autor. ${ }^{30}$

30 Como disciplinas optativas, que os alunos podem cursar do $5^{\circ}$ ao $8^{\circ}$ semestre. Encontramos, ainda, "Teoria Sociológica I: A escola alemã e seus representantes; a tradição durkheimiana" "Teoria sociológica II: Formulação 
Inicialmente, vale salientarmos que a quantidade e a qualidade de informaçôes disponibilizadas nos sítios são muito variadas. Em alguns casos, tivemos de escrever aos responsáveis para encontrar os sítios específicos. Em outros casos, encontramos ementas atualizadas pela última vez em $2008^{31}$. Apenas a título de comparação, os sítios dos nos cursos de pós-graduação em Sociologia das mesmas universidades são mais "claros e amigáveis", em comparação com aqueles dos cursos de graduação ${ }^{32}$. Em relação à estrutura da grade curricular, temos:

1. Os três primeiros semestres do curso são efetivamente dedicados à teoria clássica e/ou contemporânea, à exceção do curso de Ciências Sociais da UFRJ, que é temático e trabalha os clássicos, por exemplo, em disciplinas optativas. Em relaçáo a todos os outros cursos, as ementas se limitam a apresentar Marx, Weber e Durkheim, à exceção das Ciências Sociais na USP que apresenta a "Sociologia alemã" como um todo (Tonnies, Sombart, Simmel, Weber etc.) - e não apenas Weber -, e a UnB que apresenta Weber e Simmel;

2. Os cursos das universidades federais do Ceará, Pernambuco, Rio Grande do Sul e da Universidade de Brasília, apresentam mais de um clássico em um mesmo semestre, no caso no segundo ou o no terceiro semestres;

3. Os terceiro e quarto semestres (com exceção das federais do Ceará, Paraná e Rio Grande do Sul) são também dedicados à teoria, no caso, aos autores contemporâneos;

4. Marx aparece frequentemente antes de Weber e Durkheim;

5. O formato geral de apresentaçáo se faz pelos autores, raramente pelas correntes e/ou pela história da disciplina.

A primeira análise reforça, claramente, o argumento daqueles que criticam o "excesso de teoria" nos quatro primeiros semestres. Se somarmos as cargas teóricas nas disciplinas da Antropologia e da Ciência Política, temos

de teorias delongo alcance e o problema da generalização na Sociologia. Concepções abrangentes e suas construções teóricas. Teorias de médio alcance e seu papel mediador entre fenômenos locais e universais. A problemática da ideologia.

31 Destacamos que a ementa efetivamente dada pelo professor pode estar atualizada na sala de aula.

32 O tipo de avaliação e acompanhamento dos cursos de pós-graduação com atribuição de conceitos feita pela CAPES/MEC explica, em parte, essa discrepância. 
o caso comum de 3/4 do tempo dos alunos durante três ou quatro semestres serem dedicados exclusivamente ao estudo dos clássicos. Em alguns casos vistos, há autores - Marx e Weber, por exemplo - que têm seus textos, lidos nas disciplinas de Sociologia e de Ciência Política, como é o caso da Universidade Federal do Paraná. Importa mencionarmos, ainda, que discussóes teóricas surgem também nas disciplinas optativas. Veremos que, de maneira geral, a formação em Ciências Sociais nos cursos selecionados se não é excessivamente teórica, é fortemente acadêmica.

Uma segunda conclusão impóe-se: além de ser bastante acadêmica como um todo, e teórica nos semestres iniciais, a formação não é necessariamente plural ou atualizada. Vejamos. Todos os cursos apresentam Marx, Weber e Durkheim. No Rio Grande do Sul, fala-se em "Narrativa da Sociologia Compreensiva” e em São Paulo, na "Sociologia alemã”, mas o principal autor nos dois casos é Weber. Há forte concentração em um número pequeno de autores, nos casos do Paraná e de Sáo Paulo, estudados quase que individualmente durante todo um semestre. Nos cursos das outras universidades, os três clássicos são estudados em conjunto ao longo do mesmo semestre. Portanto, há muito tempo para um autor clássico, e esse tempo é divido por dois ou por três, pois há outro(s) autor(es) a ser(em) apresentado(s). E isso remete à forma como a teoria é ensinada. De forma resumida, constatamos que as grades estudadas parecem seguir três modelos, não necessariamente incompatíveis. Sáo eles:

A. A Teoria Sociológica segundo seus autores

O estudo da teoria sociológica através de seus autores parece uma opção natural. Aqui, basta observarmos a cronologia, fixar o período, uma vez que todos os clássicos nasceram no século XIX, e estudar suas obras. Esse partido permite personalizar a ciência, dar nomes, investigar biografias, mostrando que a ciência tem seus cânones, seus mestres de referência. Mas, escolhendo autores, eles sáo individualizados e os conhecimentos que produziram são sistematizados em grandes grades de leitura.

B. A teoria sociológica segundo suas correntes

O segundo modelo envolve o estudo da teoria segundo suas correntes, já definidas na história da disciplina e da Filosofia. Os autores tornam-se aqui funcionalistas, dialéticos, compreensivos, estruturalistas etc. Podem, ainda, estar na corrente do "conflito" em oposição à corrente "institucionalista". 
A classificação de obras e autores em correntes de pensamento naturaliza e legitima aquilo que é histórico e social. As correntes legitimam, também, a classificação daqueles que as fizeram.

C. A Sociologia Contemporânea segundo seus temas centrais

O terceiro modelo é o estudo da teoria sociológica segundo seus temas centrais. Essa abordagem tem por fundamento a escolha de temas ou de conceitos. Os autores são apresentados, e aqui comparados, através de seus conceitos. A noção de indivíduo ou de Estado ou, ainda, de classe em tal ou tal outro autor. Investiga-se assim, em detalhe, o que cada autor escolhido disse sobre determinado tema ou como definiu um conceito, em oposição a um contemporâneo ou mesmo a algum autor da atualidade.

Como visto, de forma geral, a opção das grades curriculares selecionadas é pelo modelo "autores". Essa opçáo convive, sem grandes inconvenientes, com introduçóes históricas e apresentaçóes de correntes. O que muda, substancialmente, é o espaço que se dedica a cada um dos modelos. Os autores - Marx Weber e Durkheim - são assim muito bem trabalhados em todos os cursos. Analisemos, agora, as ementas.

A análise das ementas nem sempre é fácil, seja porque nem todas estão efetivamente disponíveis nos sítios, seja porque estão relativamente desatualizadas, seja, enfim, porque se encontram em plataformas específicas, algumas delas restritas às estruturas administrativas.. Após análise, encontramos os seguintes dados. No caso dos clássicos, os textos são relativamente os mesmos, mas editados, ou seja, os alunos devem ler passagens e não os textos completos. Da mesma forma, nem sempre há textos históricos sobre o período em que os autores viveram ou textos em língua estrangeira. Faltam textos de comentadores ou críticos atuais, e, muitas vezes, encontramos apenas aqueles livros ou textos clássicos e traduzidos para o português ${ }^{33}$. Isso pode estar produzindo uma apresentação relativamente superficial, porque considera que um aprofundamento não é necessário naquele momento do curso, porque se julga que os alunos não têm maturidade suficiente e/ou conhecimento de línguas estrangeiras para que as leituras sejam mais abrangentes e aprofundadas

33 Isso é particularmente importante porque os textos clássicos, nas línguas originais, estão hoje inteira e gratuitamente disponiveis na internet. 
ou porque, efetivamente, são três ou dois clássicos para um mesmo semestre, o que, sem dúvida, limita as escolhas.

As afirmações anteriores são, contudo, dificilmente comprováveis sem um estudo mais aprofundado. Peguemos o caso da "Sociologia II" do curso de Ciências Sociais da USP. O curso é dedicado a Marx. Todos os aspectos da obra de Marx estão na ementa, da teoria da história às classes, com um último item dedicado ao "marxismo ocidental". Em princípio, tudo está bem organizado, desde o tempo dedicado até o rol de temas. Não obstante, nas referências bibliográficas, não há nenhum texto em língua estrangeira e a ementa está datada de 2008, talvez por mero esquecimento ou simplesmente porque ainda náo foi atualizada, Como saber? Vejamos, agora, o caso da UFC e da UFPE. Os três clássicos são apresentados em um mesmo semestre, segundo ou terceiro. Os semestres seguintes, nessas duas universidades, são dedicados a autores contemporâneos. Já o curso da UFSC apresenta, no segundo semestre, "o positivismo de Durkheim" no mesmo semestre do "materialismo histórico de Marx”. Já “a Sociologia Compreensiva de Weber” é apresentada ao lado "estrutural-funcionalismo de Parsons" no terceiro semestre. Sem mesmo discutir as nomenclaturas - "o positivismo de Durkheim" - podemos questionar porque razóes Weber foi aproximado de Parsons e náo de Marx, por exemplo. Pode-se igualmente questionar: por que autores são apresentados em conjunto nessa universidade e de forma diferente em outra? Quais os critérios de junção ou da apresentação em separado de autores? Como não há nenhum órgão federal geral ou mesmo profissional que discipline isso - seria o caso de haver? - não há aqui como julgarmos. Ademais, muitas vezes, temos reformulaçóes de currículos e ementas que são feitas em consequência de necessidades ou carências locais, realidades essas que fazem com que uma mesma ementa seja apresentada de maneira diversa segundo o professor responsável. Enfim, notamos que o estudo da recepção dos autores clássicos no Brasil, com as exceçóes de praxe, não goza de muito prestígio ${ }^{34}$.

Resumindo, temos uma realidade geral no Brasil estudado: Marx, Weber e Durkheim são efetivamente autores clássicos para a Sociologia brasileira. São bastante estudados em todos os cursos nos semestres iniciais. Será esse o

34 O estudo da recepção dos autores e da formação dos professores poderia explicar grandes diferenças nos formatos dos cursos de Ciências Sociais no Brasil e na Argentina, por exemplo. 
"excesso" de teoria? Seria esse suposto excesso responsável por parte da evasão nos semestres iniciais, como se comenta amiúde em fóruns da área? Isso teria mudado após a inclusão da Sociologia no Ensino Médio? Eis questóes ainda em aberto.

Em relação à teoria contemporânea, duas conclusões iniciais impóem-se: 1) Em um único semestre, muitos autores são trabalhados em diversos cursos; 2) Observa-se uma escolha algo aleatória em relação aos autores efetivamente apresentados como contemporâneos. A título de exemplo, em Pernambuco, a escolha recaiu sobre Pierre Bourdieu, Anthony Giddens; Norbert Elias; Alexis de Tocqueville, além de autores pós-modernos e pós-coloniais. Já em Santa Catarina, a escolha recaiu sobre Pierre Bourdieu, Escola de Frankfurt, Michel Foucault e Bruno Latour, entre outros. Finalmente, em Brasília, a escolha recaiu em Robert Merton, Talcott Parsons, Pierre Bourdieu, Michel Foucault etc. Na Universidade Federal do Ceará, a escolha recaiu sobre Pierre Bourdieu, Erwin Goffman, Michel Foucault, Jugen Habermas e Richard Sennet. Na Universidade de São Paulo, os contemporâneos surgem apenas a partir do quinto semestre e no curso da Universidade Federal do Paraná, e aparecem em disciplinas obrigatórias alocadas no interior de "eixos temáticos". Em resumo, em todas as ementas estudadas, apenas uma unanimidade: Pierre Bourdieu; uma aparente ausência: Alain Touraine; um viés: Sociologia europeia ${ }^{35}$. Um ponto merece destaque: autores contemporâneos efetivamente atuais - Jeffrey Alexander ou Bernard Lahire - estão ausentes do rol de contemporâneos ensinados nas disciplinas obrigatórias, o que náo significa que não sejam efetivamente lidos e estudados em outros ambientes. $\mathrm{O}$ fato é que a Sociologia contemporânea tem avançado em autores, temas e regiōes geográficas (Índia, África do Sul, Austrália, China etc.) enquanto que o espaço dedicado a ela continua o mesmo, sempre bem menor do que àquele dedicado à teoria clássica.

Outra questão subjacente, igualmente importante quando se discute o ensino da teoria, é o formato dos currículos. No caso dos cursos da UFRJ, da USP e da UnB, existem cadeias de pré-requisitos, cujo objetivo é fazer o aprendizado dos conteúdos a partir de etapas necessárias. Nessas universidades, as disciplinas optativas dependem de conhecimentos anteriormente

35 É preciso reconhecer, contudo, que os professores nem sempre seguem totalmente as ementas oficiais das disciplinas. Mesmo assim, elas revelam escolhas que foram feitas, ainda que formalmente. 
validados. Em outros, como no caso da UFPR, o curso foi dividido em "Formação geral profissional" e "formação profissional específica". Ao final do terceiro semestre, os alunos devem optar por uma das três áreas ou pela formação em licenciatura. Nesse formato, as disciplinas teóricas clássicas ficaram nos três primeiros semestres e, no caso específico da área de Sociologia, as disciplinas teóricas contemporâneas são ensinadas, também, nos "eixos temáticos" (atores, trabalho, sociedade e natureza etc.), mas de maneira livre, ou seja, nada induz o aluno a cursar a disciplina de um eixo antes daquela obrigatória do eixo temático vizinho. Em um caso e outro, a carga de leitura permanece importante e, comumente, os clássicos - por vezes os mesmos textos já lidos nas disciplinas iniciais - são retomados. A título de exemplo, vejamos o que acontece na disciplina de Sociologia do Conhecimento no curso da UFPR ${ }^{36}$. A ementa traz, como leitura obrigatória, o texto de Marx "A Ideologia Alemã". Esse mesmo texto já foi lido na disciplina "Sociologia e modernidade: o paradigma marxista". ${ }^{37}$ No caso da disciplina "Sociologia e a Cidade" 38 , o aluno lê "O Capital", volume 1, de Marx, texto que já leu na disciplina "Sociologia II", dedicada ao mesmo autor. ${ }^{39}$ Podemos multiplicar as situaçóes, as disciplinas e as universidades, e encontraríamos casos semelhantes, porque se trata de uma padráo e náo de açóes isoladas. A pergunta é: isso reforçaria a presença da teoria nas grades? Pode-se objetar que, uma vez que os alunos já leram (ou já deveriam ter lido) aquele texto, o professor da disciplina levará isso em questão, mas o fato é que o tema teórico está novamente presente, demonstrando o grande tempo dedicado à teoria e aos autores.

Em resumo, é correto afirmarmos que as grades dáo grande destaque à teoria sociológica. Ressaltamos que, em todas as universidades analisadas, os alunos têm carga teórica de leitura também nas disciplinas de Antropologia e de Ciência Política, o que torna o número de textos ainda maior. Assim, é possível imaginar que, em uma mesma manhã, alunos podem estar (de fato estáo) lendo Weber em disciplinas da Ciência Política e da Sociologia, Durkheim, em disciplinas da Antropologia e da Sociologia, e assim por diante. Isso ocorre, em parte, porque a forma de desenvolver os conteúdos programáticos é

36 Ver a ementa em Universidade Federal do Paraná, 20 I lb.

37 Ver a ementa em Universidade Federal do Paraná, 201 la.

38 Ver a ementa em www.uspdigital.usp.br/jupiterweb/obterDisciplina?sgldis=FSL0525 Ecodcur=8040Ecodhab $=103$

39 Ver a ementa em www. uspdigital.usp.br/jupiterweb/obterDisciplina?sgldis=FSLOI02Ecodcur=8040Ecodhab=103 
de responsabilidade do professor de cada área ou departamento e, nas maiores universidades, há departamentos específicos para cada área, diminuindo, ainda mais, o contato entre os docentes do mesmo curso. Da mesma forma, mesmo quando não existem departamentos específicos, há pós-graduaçôes específicas $^{40}$. Enfim, ao contrário dos cursos de pós-graduação, constantemente avaliados e financiados em funçáo dos conceitos recebidos, os cursos de graduação nas universidades federais são pouco avaliados. Quando isso ocorre, utiliza-se o formulário de avaliação desenvolvido pelo INEP, e essas avaliaçóes não envolvem critérios de repasse de recursos, mas tão somente de reconhecimento ou de (re)credenciamento dos cursos.

\section{Considerações finais}

O debate aqui engajado é sobre o lugar, o espaço e o conteúdo da teoria sociológica nos cursos de Ciências Sociais. De fato, o lugar é no início, sempre. Pode-se sempre questionar essa escolha.

No curso de Ciências Sociais da Universidade Estadual de Londrina, a teoria foi colocada nos semestres mais avançados. Esse é também o modelo seguindo pelo curso de Ciências Sociais da UFRJ, onde as teorias clássicas aparecem mesmo como optativas. Em conversas informais com colegas dessas instituiçôes, eles alegam que a grande vantagem dessa inversáo é cativar os alunos a partir dos problemas e temas sociais stricto sensu, mostrando como os assuntos são construídos sociologicamente ao invés de simplesmente apresentarem autores por vezes desconhecidos. Ao mesmo tempo, em Londrina procura-se ensinar como se elabora uma pesquisa, o fazer sociológico. E aí, com "a mão na massa", fazendo a famosa revisão da literatura, surge a importância da teoria. Embora não tenha sido pensado nesses termos, para a dita geração $\mathrm{Y}^{41}$, segundo os colegas com quem conversamos na Universidade Estadual de Londrina, esse modelo é descrito como mais instigante.

O espaço dedicado à teoria é efetivamente grande. Sáo praticamente quatro semestres em que o estudo da teoria sociológica reina majoritariamente, ocupando praticamente $75 \%$ do tempo da formação se somarmos as disciplinas

40 No caso da USP, UFRGS, UFPR, por exemplo, as três pós-graduações existem, o que aumenta ainda mais a especialização e, por conseguinte, a distância entre os colegas dessas áreas.

4 I Termo atribuido àqueles que sempre portam fones de ouvido, em forma de " $\gamma$ ". 
teóricas das três áreas. Consideramos que é interessante citarmos, ainda, que o espaço dedicado à teoria não se limita aos quatro primeiros semestres, mas avança pelos demais por meio das disciplinas optativas, sempre abertas pela leitura dos textos dos autores clássicos e contemporâneos que fundaram aquele subcampo. Em consequência, a teoria está no início, mas também no final do curso, e até mesmo nos TCCs, estes geralmente iniciados por uma revisão da literatura (obrigatoriamente, composta por autores clássicos e contemporâneos) sobre o tema escolhido. Mas, se o espaço da teoria é efetivamente grande, ele multiplica-se por três devido à formação nas três áreas, a saber: Antropologia, Ciência Política e Sociologia. De fato, é o formato dos cursos analisados que está na origem disso. Um segundo semestre típico de um aluno de Ciências Sociais, nas universidades estudadas, é preenchido por três disciplinas teóricas, com títulos que podem perfeitamente ser, Antropologia II, Ciência Política II e Sociologia II, acrescidos de uma história do Brasil e uma disciplina metodológica (ou estatística). Isso se repete de maneira quase idêntica até o quarto semestre, quando surge uma disciplina pedagógica, para aqueles que optam pela licenciatura.

Em terceiro lugar, analisamos o conteúdo da teoria. Aqui, foram percebidas duas realidades contrastantes. Do lado da teoria clássica, há grande limitaçáo; do lado da teoria contemporânea, muita variedade. Como regra, os clássicos são Marx Weber e Durkheim. E aqui, Auguste Comte, acolá, Georg Simmel ou Alexis de Tocqueville, necessariamente presentes também nas disciplinas de Ciência Política. Já nas disciplinas contemporâneas, existe muita variedade, uma única unanimidade (Pierre Bourdieu) e muitas ausências de autores atuais como Jeffrey Alexander, Bernard Lahire ou François Dubet.

Cabe, ainda, pensarmos como está sendo ensinada a teoria sociológica? O formato atual de concentração das disciplinas nos primeiros semestres através do modelo "autores" pode indicar que o conteúdo seja ensinado de maneira datada e estanque. Contudo, não realizamos pesquisa empírica junto aos professores que ministram esses cursos e assim, nada podemos concluir aqui.

A especialização das carreiras dos docentes é outro fator que não analisamos. Não analisamos tampouco a relaçáo que os professores de teoria das três áreas - Antropologia, Ciência Política e Sociologia - mantém entre si. Há, porém, um problema evidente. A carreira universitária leva à especialização dos professores, mas o formato do curso - nas três áreas - demanda que o 
aluno tenha conhecimento das três áreas. E essa incompatibilidade entre especialização e formação "beira a esquizofrenia"; afinal, por vezes, pode fazer o aluno acumular mais conhecimento transversal e geral do que o próprio professor. Com efeito, seria possível perguntar se algum professor hoje de Ciências Sociais no Brasil domina a variedade de teorias e abordagens que os alunos aprendem nas três áreas.

Outra possível consequência desse formato é a apresentação dos clássicos somente a partir dos enfoques disciplinares. Assim, Marcel Mauss, que escreveu com Durkheim, não é sociólogo e está ausente das ementas estritamente sociológicas dedicadas ao mestre de Bordeaux42. Da mesma forma, os escritos estritamente políticos de Marx estáo ausentes das ementas analisadas das disciplinas sociológicas. Isso permite que se questione o modelo de curso de Ciências Sociais dividido em três áreas de formação, uma realidade que está longe de ser uma regra mundo afora.

A pesquisa sobre os grupos de pesquisa registrados, aparentemente lateral ao objetivo desse texto, permitiu verificar que a teoria como campo de pesquisa tem poucos seguidores e a pesquisa em teoria de modo interdisciplinar parece ser inexistente. A presença de Grupos de Trabalho na SBS e na ANPOCS parece indicar grande apreço pelos estudos teóricos, mas isso náo se traduz em termos de número de pesquisadores efetivamente cadastrados. Não temos dados, nem foi objetivo aqui, compreender essa realidade. Contudo, devido ao pouco interesse despertado pela questáo, pareceu-nos interessante tentar relacionar o estudo sobre o lugar do ensino da teoria nas grades curriculares e a quantidade de grupos que efetivamente estudam a teoria.

Uma análise mais completa da realidade do ensino da teoria demandaria certamente entrevistas com professores, alunos e um estudo mais acurado dos Projetos Pedagógicos. Tais lacunas não invalidam, contudo, os dados e as análises feitas. Finalmente, o caráter restrito e náo amostral (por isso, incompleto) do campo selecionado faz com que as análises aqui sejam alertas, pontos para um debate novo e que se faz necessário.

42 Esse partido das Ciências Sociais brasileiras tem um exemplo forte na discussão sobre a dita fase antropológica de Florestan Fernandes, interpretação no mínimo discutivel quando se sabe a pequena diferenciação disciplinar entre as áreas naquela época, conforme aludimos acima. 


\section{Referências}

ARAÚJO, S. M. de; BRIDI, M. A.; MOTIM, B. L. Sociologia. São Paulo: Editora Scipione, 2013. ASSOCIAÇÃO BRASILEIRA DE ENSINO DE CIÊNCIAS SOCIAIS. 2015. Disponível em: www.abecs.com.br>. Acesso em: 29 set. 2014.

ASSOCIAÇÃO NACIONAL DE PROGRAMAS DE PÓS-GRADUAÇÃO. www.anpocs.org.br BOITO JR., A.; MOTTA, L. E. Marx in Brazil. Socialism and Democracy, v. 24, n. 3, p. $155-$ $160,2010$.

BOMENY, H.; EMERIQUE, R. B.; FREIRE-MEDEIROS, B.; O’DONNEL, J. Tempos modernos, tempos de sociologia. São Paulo: Editora do Brasil, 2013.

BOTELHO, A.; CARVAlHO, L. C. A sociedade em movimento: dimensóes da mudança na sociologia de Maria Isaura Pereira de Queiroz. Sociedade e Estado, v. 26, n. 2, p. 209-238, maio/ ago. 2011. Disponível em: <http://periodicos.unb.br/index.php/estado/issue/view/692/showToc>. Acesso em: 29 set. 2014.

BRASIL. Ministério da Educação e Cultura. Secretaria de Educação Básica. Fundo Nacional de Desenvolvimento da Educação. Guia de livros didáticos: PNLD 2015: Ensino Médio: Sociologia. Brasília, DF: MEC, 2014. Disponível em: <http://www.fnde.gov.br/programas/livro-didatico/ guias-do-pnld/item/5940-guia-pnld-2015>. Acesso em: 28 set. 2014.

CÂNDIDO, A. A Sociologia no Brasil. Enciclopédia Delta Larousse. 2. ed. Rio de Janeiro: Delta S. A., 1957. v. 4. p. 2216-2232.

CANO, I. Nas trincheiras do método: o ensino de metodologia das Ciências Sociais no Brasil. Sociologias, v. 14, n. 31, p. 94-119, 2012.

CARDOSO, F. H. Capitalismo e escravidáo no Brasil meridional. 5. ed. rev. Rio de Janeiro: Civilização Brasileira, 2003.

CARVAlHO, L. M. G. X. de. Sociologia e Ensino em debate: experiências e discussão de sociologia no ensino médio. Ijuí: Ed. Unijuí, 2004.

Sociologia e Filosofia no Ensino Médio: mudanças profundas na educação brasileira.

Trilhas Filosóficas, ano I, n. 1, p. 117-127, 2008.

CENTRO BRASILEIRO DE ESTUDOS DURKHEIMIANOS. 2015. Disponível em: <http:// www.durkheim-br.org>. Acesso em: 28 set. 2014.

CHACON, W. História das ideias sociológicas no Brasil. São Paulo: Edusp; Grijalbo, 1977. 
COHN, G. Crítica e resignação: Max Weber e a teoria social. 2. ed. São Paulo: Martins Fontes, 2003. COSTA, C. Sociologia: Introdução à ciência da sociedade. São Paulo: Editora Moderna, 1987.

FAORO, R. Os Donos do Poder: Formaçáo do Patronato Político Brasileiro. Rio de Janeiro: Editora Globo, 2 vols, 1989.

FERNANDES, F. A organizaçáo social dos Tupinambá. São Paulo: Instituto Progresso Editorial, 1949.

. A Função Social da Guerra na Sociedade Tupinambá. Revista do Museu Paulista, v. 6, p. 7-425, 1952.

Fundamentos empíricos da explicaçáo sociológica. São Paulo: CEN, 1959.

Ensaios de Sociologia Geral e Aplicada. São Paulo: Pioneira Editora, 1960.

Elementos de Sociologia Teórica. São Paulo: CEN, 1970.

A natureza sociológica da Sociologia. São Paulo: Ática, 1980.

FERREIRA, D. Manual de Sociologia: dos clássicos à sociedade da informação. 2. ed. São Paulo: Ática, 2003.

HALLEWELL, L.; LESSA, S The situation of Marxism in Brazil. Latin American Perspectives, v. 25 , n. 1, p. 94-108, 1998.

IANNI, O. As metamorfoses do Escravo. São Paulo: Difusão Européia do Livro, 1962.

Estado e capitalismo no Brasil. Rio de Janeiro: Civilização Brasileira, 1965.

Dialética e capitalismo: ensaio sobre o pensamento de Marx. Petrópolis: Vozes, 1982.

LIEDKE FILHO, E D. A Sociologia no Brasil: história, teorias e desafios. Sociologias, ano 7 , n. 14, p. 376-437, 2005.

LIMA, P. L. Entrevista com Fernando Henrique Cardoso. Revista Estudos Políticos, Rio de Janeiro, n. 6, p. 7-21, 2013. Disponível em: <http://revistaestudospoliticos.com/wp-content/ uploads/2013/10/6p7-21.pdf>. Acesso em: 29 set. 2014.

MELO, M. P. da C. Especialidades e linhagens da ciência social brasileira: um estudo bibliométrico. In: MAIO, M. C.; VILLAS-BÔAS, G. K. (Org.). Ideais de modernidade e Sociologia no Brasil: Ensaios sobre Luiz Aguiar da Costa Pinto. Porto Alegre: Editora da UFRGS, 1999. p. 301-328.

MENEZES, D. La sociologia enel Brasil. In: GURVITCH, G.; MOORRE, W. E. La Sociologia delsiglo XX. 2. ed. Barcelona: Libreria El Ateneo Editorial, 1965. Tomo II. p. 197-225. 
MICELI, S. (Org.). História das Ciências Sociais no Brasil. São Paulo: Sumaré/FAPESP, 1989. v. 1.

História das Ciências Sociais no Brasil. São Paulo: Sumaré/FAPESP, 1995. v. 2.

O que ler na ciência social brasileira (1970-1995) - Sociologia. São Paulo: Sumarél ANPOCS; Brasília: CAPES, 1999.

MORAES, A. C. de. Licenciatura em Ciências Sociais e Ensino de Sociologia: entre o balanço e o relato. Tempo Social, São Paulo, v. 15, n. 1, p. 5-20, 2003.

- (Coord.). Explorando o ensino: Sociologia. Brasília: MEC. Coleção Explorando o Ensino, 2010. v. 15.

MORAES FILHO, E. Simmel. São Paulo: Ática, 1983. v. 34. (Coleção Grandes Cientistas Sociais):

OLIVEIRA, A. Revisitando a História do Ensino de Sociologia na Educação Básica. Acta Scientiarum - Education, Maringá, v. 35, n. 2, p. 179-189, Jul./dez. 2013.

OLIVEIRA, L. F. et al. Sociologia para jovens do século XXI. Rio de Janeiro: Editora Imperial Novo Milênio, 2007.

OLIVEIRA, M. de. O Estado em Durkheim. Elementos para debate sobre sua sociologia política. Revista de Sociologia e Política, Curitiba, v. 18, n. 37, p. 125-135, out. 2010.

. O conceito de Representações coletivas: uma trajetória da Divisão do Trabalho às Formas Elementares. Debates do NER, Porto Alegre, ano 13, n. 22 p. 67-94, jul./dez. 2012. Florestan Fernandes: teoria e indiferenciação disciplinar entre os anos 1940 e 1960. In: CONGRESSO DA SBS, 17., 10-13 set. 2013. Anais Eletrônicos... Salvador: UFBA, 2013. Disponível em: <www.sbsociologia.org.br>. Acesso em: 29 set. 2014. . ; WEISS, Raquel A. (Org.). A atualidade de Davi Emile Durkheim. Curitiba: Editora da UFPR, 2011.

OLIVEIRA, P. S. de. Introduçáo à Sociologia. 24. ed. São Paulo: Ática, 2001.

NOGUEIRA, O. A Sociologia no Brasil. In: FERRI, M. G.; MOTOYAMA, S. História das ciências no Brasil. São Paulo: EPU, 1981. v. 3. p. 181-234.

PEIRANO, M. G. S. (Org.). Uma antropologia no plural: três experiências contemporâneas. Brasília: Editora UnB, 1992.

PESSANHA, E. G. da; VILLAS BÔAS, G. K. (Org.). Ciências Sociais: ensino e pesquisa na graduação. Rio de Janeiro: Jornada Cultural, 1995. 
PIERUCCI, A. F. O desencantamento do mundo: todos os passos do conceito em Max Weber. São Paulo: Editora 34, 2003.

PORTO ALEGRE, Maria S. O visível e o oculto na cultura brasileira. In: KOSMINSKY, E. V. (Org.). Agruras e prazeres de uma pesquisadora: ensaios sobre a sociologia de Maria Isaura Pereira de Queiroz. Marília: UNESP; São Paulo: FAPESP, 1999. p. 51-65.

QUEIROZ, Maria I. P. de. Sobre Durkheim e as Regras do Método Sociológico. Ciência e Trópico, Recife, v. 23, n. 1, p. 75-84, 1995.

RODRIGUES, J. A. (Org.). Durkheim. São Paulo: Ática, 1977. (Coleção Grandes Cientistas Sociais).

RODRIGUES, L. S. A produção social do marxismo universitário em São Paulo: mestres, discípulos e "um seminário" (1958-1978). 2011. 565 f. Tese (Doutorado em História Social) - Programa de Pós-Graduação História Social, Universidade de São Paulo, São Paulo, 2011.

SELL, C. E. Max Weber e a racionalização da vida. Petrópolis: Editora, 2014.

SILVA, I. L. F. O Ensino das Ciências Sociais/Sociologia no Brasil: histórico e perspectivas. In: MORAES, A. C. de (Coord.). Explorando o Ensino: Sociologia. Brasília: MEC, 2010. v. 15, p. 23-31. (Coleçáo Explorando o Ensino).

SOCIEDADE BRASILEIRA DE SOCIOLOGIA. www.sbsociologia.com.br

SOCIEDADE BRASILEIRA DE SOCIOLOGIA. Carta Aberta do Encontro Nacional do PIBID Ciências Sociais/Sociologia. 6 jun. 2014. Disponível em: <http://www.sbsociologia.com. br/home/index.php?formulario=noticias\&metodo=0\&id=13>. Acesso em: 28 set. 2014.

SOCIOLOGIA. (2006). Vários autores. Curitiba: SEED

SOUZA, J. J. F. A atualidade de Max Weber. Brasília: Editora da UnB, 2000.

.; ÖLZE, B. (Org.). Simmel e a modernidade. 2. ed. Brasília: Editora da UnB, 2005.

UNIVERSIDADE FEDERAL DO PARANÁ. Setor de Ciências Humanas. Letras e Artes. Departamento de Ciências Sociais. 2011a. Ementa de disciplina - HC 635: Sociologia e modernidade: Paradigma Marxista. Disponível em: <http://www.cienciassociais.ufpr.br/ documentos/HC635B-2011.pdf>. Acesso em: 28 set. 2014.

Ementa de disciplina - HC 25: Sociologia do Conhecimento. 2o sem. 2011 b.

Disponível em: <http://www.humanas.ufpr.br/portal/cienciassociais/files/2011/09/HC125-2011. pdf>. Acesso em: 28 set. 2014.

VILLAS-BÔAS, G. Currículo, iniciação científica e evasão de estudantes de ciências sociais. Tempo Social, São Paulo, v. 15, n. 1, p. 45-62, 2003. 
. A recepção da Sociologia alemã no Brasil. Rio de Janeiro: Topbooks, 2006.

. A tradição renovada na obra de Maria Isaura Pereira de Queiroz. In: BOTELHO, A.; SCHWARCZ, L. M. Um enigma chamado Brasil. 29 intérpretes e um país. Sáo Paulo: Cia das Letras, 2009. p. 282-295.

Para ler a sociologia política de Maria Isaura Pereira de Queiroz. Revista de Estudos

Políticos, São Paulo, n. 1, p. 37-44, 2010. Disponível em http://revistaestudospoliticos.com/paraler-a-sociologia-politica-de-maria-isaura-pereira-de-queiroz-por-glaucia-villas-boas/. Acessado em 18 de setembro de 2014.

WAIZBORT, L. As aventuras de Georg Simmel. São Paulo: Editora 34, 2000.

. Simmel no Brasil. Dados - Revista de Ciências Sociais, v. 50, n. 1, p. 11-48, 2007.

WEISS, R. A. Durkheim e as formas elementares da vida religiosa. Debates do NER, Porto Alegre, ano 13, n. 22 p. 95-119, jul./dez. 2012.

. O sagrado e a moralidade laica na teoria moral durkheimiana. Revista Pós-Ciências Sociais, v. 10, p. 47-68, 2013.

Recebido em: 10.07.2015

Aceito em: 20.10.2015

\section{The teaching of Sociological theory in some Social Sciences courses in Brazil's public universities}

\section{Abstract}

This paper aims to analyze the role that teaching of sociological theory has within undergraduate courses of Social Sciences in federal universities of Ceará, Pernambuco, Rio de Janeiro, Paraná, Santa Catarina e Rio Grande do Sul, and the universities of Brasília and São Paulo, all of them in Brazil. We begin to analyze the history of sociological theory in Brazil. We present the theory research groups in activity today. We can see that research in sociological theory plays second role in Brazilian Sociology. Analyzing the curriculum of the courses and the menus of theoretical disciplines, we show then that the most of time dedicated to sociological theory in those courses, particularly for classical theory, in the first two years. Nevertheless, the content is almost the same, limited to Marx, Weber and Durkheim. In relation to contemporary sociology, the situation is quite different and there is no consensus. In despite of great importance and time dedicated to the teaching of theory, there are no formal discussions about how to teach it in methodological and epistemological terms.

Keywords: Social sciences courses. Teaching. Sociological theory. University 